\title{
Bis(arylimidazole) Iridium Picolinate Emitters and Preferential Dipole Orientation in Films
}

\author{
Aron J. Huckaba, ${ }^{\dagger}$ Alessia Senes, ${ }^{\ddagger} \S$ Sadig Aghazada, ${ }^{\dagger}$ Azin Babaei, ${ }^{\prime \prime}$ Stefan C. J. Meskers, ${ }^{\S}$
} Iwan Zimmermann, ${ }^{\dagger}$ Pascal Schouwink, ${ }^{\perp}$ Natalia Gasilova, ${ }^{\perp}$ René A. J. Janssen, ${ }^{\mathcal{\infty}}{ }^{\circledR}$ Henk J. Bolink, ${ }^{\| \oplus}$ and Mohammad Khaja Nazeeruddin*, ${ }^{+}$이

${ }^{\dagger}$ Group for Molecular Engineering of Functional Materials, Institute of Chemical Sciences and Engineering, and ${ }^{\perp}$ Institute of Chemical Sciences and Engineering, Ecole Polytechnique Federale de Lausanne Valais Wallis, Rue de l'Indutrie 17, 1950 Sion, Valais, Switzerland

${ }^{\ddagger}$ Holst Centre/TNO, High Tech Campus 31, P.O. Box 8550, 5605 KN Eindhoven, The Netherlands

${ }^{\S}$ Molecular Materials and Nanosystems and Institute for Complex Molecular Systems, Eindhoven University of Technology, P.O. Box 513, 5600 MB Eindhoven, The Netherlands

"Instituto de Ciencia Molecular, Universidad de Valencia, c/Catedrático J. Beltrán 2, 46980 Paterna, Spain

\section{Supporting Information}

ABSTRACT: The straightforward synthesis and photophysical properties of a new series of heteroleptic iridium(III) bis(2-arylimidazole) picolinate complexes are reported. Each complex has been characterized by nuclear magnetic resonance, UVvis, cyclic voltammetry, and photoluminescent angle dependency, and the emissive properties of each are described. The preferred orientation of transition dipoles in emitter/host thin films indicated more preferred orientation than homoleptic complex $\operatorname{Ir}(\text { ppy })_{3}$.

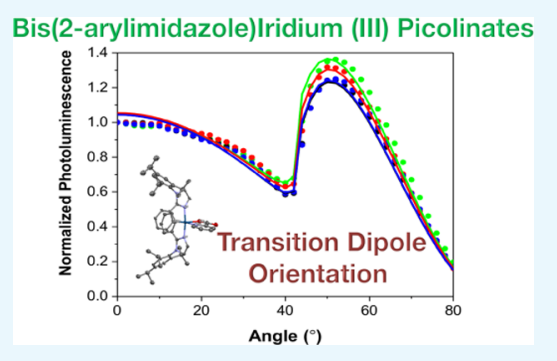

\section{INTRODUCTION}

In the search for efficient light-emitting devices, organic lightemitting diodes (OLEDs) offer a full-spectrum inexpensive option because of the development of heavy atom emitters. Spin-orbit coupling (SOC) is strong in third-row elements and allows for theoretical device efficiency to be near unity by utilizing both singlet and triplet excitons for light generation. ${ }^{1,2}$ Ir complexes have been successful thus far, thanks to roomtemperature ( $\mathrm{rt}$ ) emission, strong SOC that allows efficient phosphorescence from its ${ }^{3}$ MLCT state, $\mu$ s time range excited state lifetime, and high photoluminescence quantum yield (PLQY). ${ }^{3-6}$

Ir(III) emitters exhibiting emission of every color, especially green and red, have been synthesized to date. Concerning green OLEDs, emitters such as $\operatorname{Ir}(\mathrm{ppy})_{2}(\mathrm{acac})$ (Figure 1) have delivered up to $54 \%$ external quantum efficiency (EQE) in devices. ${ }^{7}$ Complexes such as $\operatorname{Ir}\left(\mathrm{MDQ}_{2}(\mathrm{acac})\right.$ (Figure 1) (MDQ $=$ methyldibenzo[f,h]quinoxaline) can provide $>20 \%$ EQE in red-emitting OLED devices. ${ }^{8}$ Quinoline-based ligands are better electron acceptors than pyridine because of the resonance stabilization energy of the phenyl moiety. ${ }^{9}$ Furthermore, the additional $\pi$ electrons and reduced donation power of the quinoline moiety in comparison to pyridine contribute to the stabilization of the emissive triplet state.

Emitters in the blue region, however, have been rare because of the high-energy excited state. ${ }^{5}$ The current state- of- the- art blue emitters have structures such as $(\mathrm{dfppy})_{2} \operatorname{Ir}(\mathrm{pic})$, called

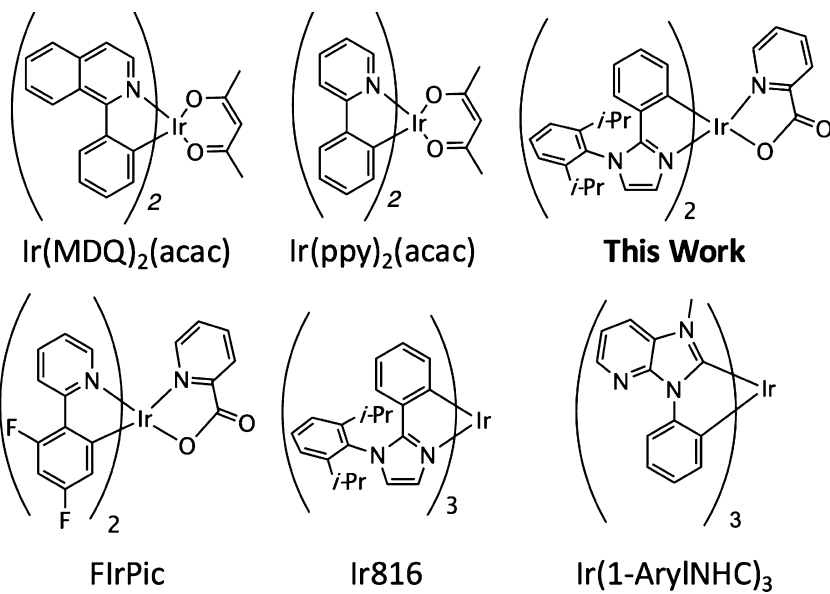

Figure 1. Structures of state-of-the-art iridium complexes and iridium complexes investigated in this study.

FIrPic $)[$ dfppy $=2$-(2,4-difluorophenyl)pyridine and pic $=$ picolinate $]^{10,11} \operatorname{Ir}(1 \text {-Aryl-NHC })_{3},{ }^{12}[\mathrm{NHC}=\mathrm{N}$-heterocyclic carbene], or $\operatorname{Ir}(2 \text {-arylimidazole) })_{3}$, as in Ir816 (Figure 1)]. ${ }^{13,14}$ Each class of emitters has its drawbacks, such as low color

Received: January 23, 2018

Accepted: February 9, 2018

Published: March 6, 2018 
Scheme 1. Synthesis of Ir Complexes 6-14
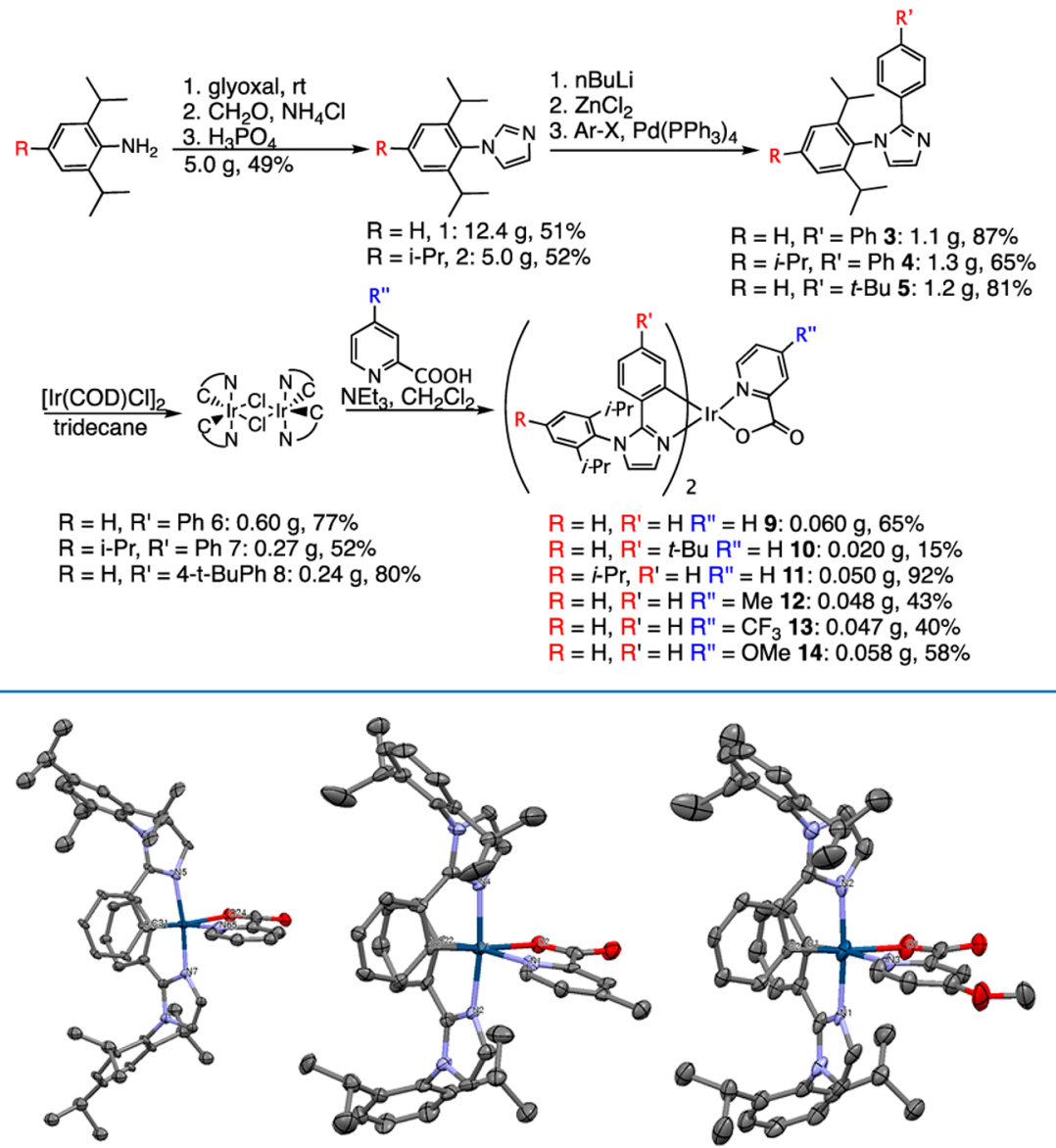

Figure 2. ORTEP plot of the crystallographically determined structures of complexes 11 (left), 12 (center), and 14 (right) (thermal probability ellipsoids are drawn at the $50 \%$ probability level). Hydrogen atoms and solvated molecules are omitted for clarity.

purity, poor stability, or poor tunability. With FirPic, for example, the strongly electron-withdrawing difluorophenyl moiety stabilizes the molecular ground state (with electron density primarily on the cyclometallated phenyl ring) more than the excited state (with electron density primarily on the pyridine ring). ${ }^{15,16}$ Such energy level tuning widens the highest occupied molecular orbital-lowest unoccupied molecular orbital (HOMO-LUMO) gap, thus increasing emission energy to the blue region. Selective functionalization of either cyclometallating phenyl or picolinate ligand has been shown to modify emission energy, PLQY, excited state lifetime, and so forth.

In homoleptic (1-Aryl-NHC) iridium complexes, sufficiently withdrawing $\mathrm{NHC}$ moieties can harbor a high-energy excited state, leading to blue emission. However, in homoleptic (2arylimidazole) iridium complexes, the excited state lies on the wingtip aryl moiety, leading to blue emission. ${ }^{17}$ Both these types of complexes are synthetically more challenging to modify than arylpyridine complexes. Accordingly, many fewer studies have investigated the chemistry of these high-performing ligands, ${ }^{18,19}$ especially in heteroleptic complexes. ${ }^{20,21}$ The goal of this investigation was to develop a deeper understanding of emitter structure-property relationships in green- to redemitting heteroleptic 1-arylimidazole iridium complexes. We report the synthesis and characterization of a series of functionalized heteroleptic bis(2-arylimidazole) iridium(III) picolinate complexes and indicate photophysical ramifications for ligand functionalization. This manuscript has been previously deposited on ChemRxiv. ${ }^{22}$

\section{RESULTS AND DISCUSSION}

Synthesis of Iridium Complexes. To experimentally establish a structure-function relationship for this class of ligands, we envisioned a series of complexes with functionalization on both wingtip and cyclometallating phenyl moieties (Scheme 1). Wingtip-modified ligands were reached by first synthesizing the appropriate imidazole with reproducible yields of nearly $50 \%$ and then coupling the appropriate aryl bromide through a key Negishi coupling reaction. This procedure reproducibly yielded each of the imidazole ligands 3-5 with good yields of $65-87 \%$.

After forming chloride-bridged iridium dimers with each ligand at high temperatures in acceptable yields of $52-80 \%$, heteroleptic picolinate complexes were obtained after ligation with commercially available picolinate ligands to form complexes 9-12 with yields between 15 and 92\%.

After synthesis and chromatography, X-ray quality single crystals of complexes 11, 12, and 14 were grown from a concentrated solution of $\mathrm{CDCl}_{3}$, and the solved structures are shown in Figure 2. Details of single-crystal X-ray diffraction (SC-XRD) experiments are given in the Supporting Information, along with CIF files. In the crystal structure of each complex, the Ir atom adopts the expected distorted octahedral geometry. Planar 2-arylimidazole ligands are perpendicular with 
Table 1. Electrochemical and Optical Properties of Ir Complexes 9-14

\begin{tabular}{|c|c|c|c|c|c|c|}
\hline complex & $\varepsilon^{a}\left(10^{4} \mathrm{~mol} \mathrm{~L}^{-1} \mathrm{~cm}^{-1}\right)$ & $\begin{aligned} & \lambda_{\max }^{a}(\text { emission }) \\
&(\mathrm{nm})\end{aligned}$ & $E\left(T_{1}\right)^{b}(\mathrm{eV})$ & $\begin{array}{c}E_{(\mathrm{S}+/ \mathrm{S})}{ }^{c} \\
(\mathrm{~V} \text { vs } \mathrm{NHE})\end{array}$ & $\begin{array}{c}E_{\text {HOMO }}^{d} \\
(\mathrm{eV} \text { vs vacuum })\end{array}$ & $\begin{array}{c}E_{\mathrm{LUMO}}^{\text {est }}{ }^{e} \\
(\mathrm{eV} \text { vs vacuum })\end{array}$ \\
\hline 9 & 316 (1.32), $336(1.30), 376(0.75), 402(0.53)$ & 571 & 2.59 & 1.13 & -5.73 & -3.14 \\
\hline 10 & $\begin{array}{l}336(1.54), 377,(0.98), 400 \text { (sh, } 0.74), 463 \\
\quad(0.025)\end{array}$ & 577 & 2.43 & 1.05 & -5.65 & -3.22 \\
\hline 11 & $\begin{array}{l}314(1.11), 342 \text { (0.94), } 371 \text { (sh, 0.57), } 402 \\
\quad(0.33)\end{array}$ & 571 & 2.59 & 1.13 & -5.73 & -3.14 \\
\hline 12 & $\begin{array}{l}318(1.64), 335 \text { (sh, 1.49), } 372(0.90), 399 \\
\quad(0.61)\end{array}$ & 555 & 2.65 & 1.12 & -5.72 & -3.07 \\
\hline 13 & 338 (1.28), 368 (1.13), 397 (sh,), $462(0.12)$ & 654 & 2.30 & 1.18 & -5.78 & -3.48 \\
\hline 14 & $\begin{array}{l}317(1.50), 337 \text { (sh, 1.27), } 372(0.79), 402 \\
\quad(0.54)\end{array}$ & 555 & 2.70 & 1.11 & -5.71 & -3.01 \\
\hline
\end{tabular}

${ }^{a}$ Measured in degassed $\mathrm{MeCN} .{ }^{b}$ Value obtained by taking the high-energy onset of the emission spectrum and converting to eV using the formula $E(T)=1240(\mathrm{eV} / \mathrm{nm}) / \lambda_{\text {onset }}(\mathrm{nm}) .{ }^{c}$ Measured in a $0.1 \mathrm{M} \mathrm{Bu}_{4} \mathrm{NPF}_{6}$ in MeCN solution with the glassy carbon working electrode, Pt reference electrode, and Pt counter electrode with ferrocene as an internal standard. Values estimated by taking $E_{\mathrm{pa}}$ and are reported versus NHE. ${ }^{d}$ Value obtained from the equation $E_{\mathrm{HOMO}}=-4.6 \mathrm{eV}-E_{\left(\mathrm{S}_{+} / \mathrm{S}\right)} .{ }^{e}$ Value estimated by adding $E_{\mathrm{HOMO}}$ and the $E\left(T_{1}\right)$.

chelating nitrogen atoms opposite to each other, which is also observed in (ppy) ${ }_{2} \operatorname{Ir}\left(\right.$ pic) complexes. ${ }^{23,24}$ Bond angles and distances were typical of other Ir(III) structures in a distorted octahedral, with no significant steric interactions.

Optoelectronic Characterization. Once the complexes were synthesized, we characterized them by cyclic voltammetry to better understand the structure-function relationship (Table 1, Figure 3). Complex 10, with the least-accepting cyclo-

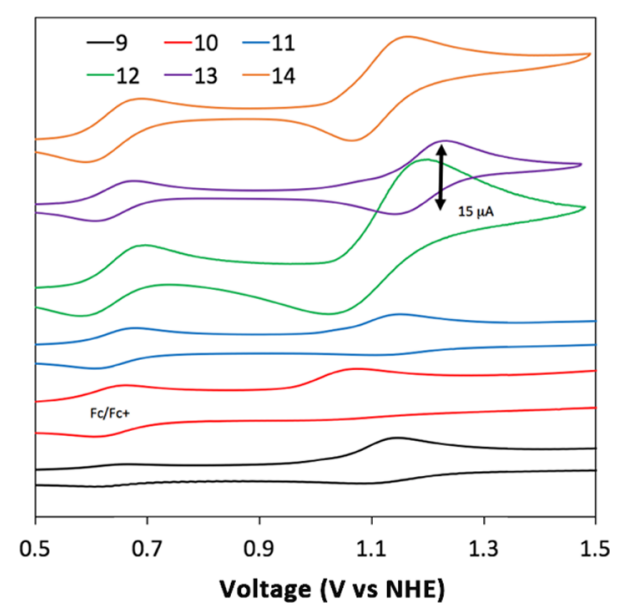

Figure 3. Measured in a $0.1 \mathrm{M} \mathrm{Bu}_{4} \mathrm{NPF}_{6}$ in $\mathrm{MeCN}$ solution with a glassy carbon working electrode, $\mathrm{Pt}$ reference electrode, and $\mathrm{Pt}$ counter electrode with ferrocene as an internal standard. Values are reported vs NHE using the conversion $\mathrm{Fc} / \mathrm{Fc}^{+}=0.64 \mathrm{~V}$ vs $\mathrm{NHE}$ in $\mathrm{MeCN}^{25}$

metallating ligand, had the most destabilized ground state oxidation potential $\left(E_{\left(S_{+} / S\right)}\right)$ value, while complex 11, with the least-accepting wingtip functionality, showed no change compared to complex 9 with the unmodified ligand.

This indicated that modification of the wingtip aryl group does not affect the molecular ground state. Complex 14, with the most accepting picolinate ancillary ligand, displayed the most stabilized $E_{(\mathrm{S}+/ \mathrm{S})}$ at $1.11 \mathrm{~V}$ versus NHE. Decreasing the electron-accepting power of the picolinate complex through substitution with more inductive and resonance donating functional groups as in complexes 9, 12, and 13 led to successively most destabilized $E_{\left(S_{+} / S\right)}$ values (from 1.12 for $\mathbf{1 2}$, 1.13 for 9 , and 1.18 for 13 ), which indicated that the picolinate directly affected the molecular ground state energy, as is the case for FIrPic and its derivatives.
To understand how structural changes affected emission, we measured the UV-vis and photoluminescence of each complex dissolved in MeCN (Table 1, Figure 4). Overall, the UV-vis

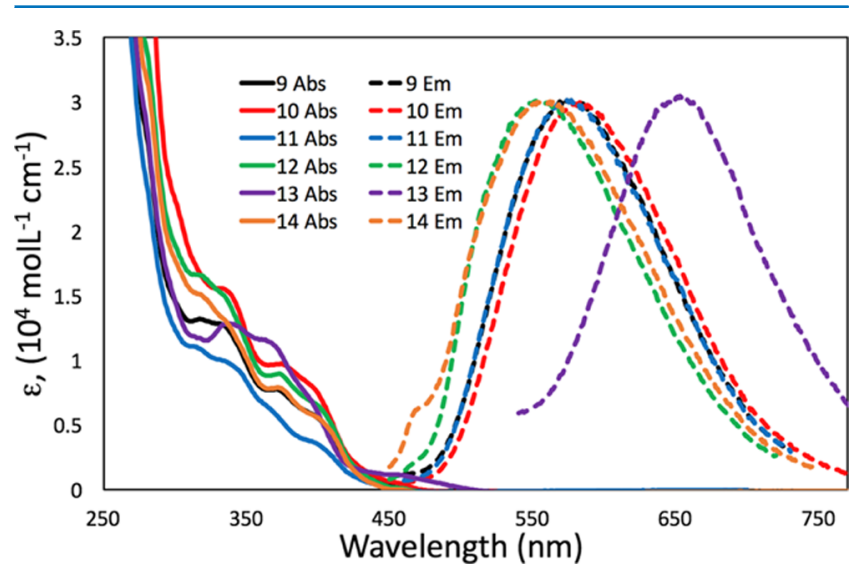

Figure 4. UV-vis and normalized photoluminescence spectra of complexes 9-14 dissolved in Ar-saturated MeCN.

absorbance spectra looked qualitatively similar for each of the complexes, as was expected. Looking more closely at the spectra, subtle differences are apparent.

For instance, compared to complex 9 (unmodified ligand), decreasing the electron-accepting power of the cyclometallating ligand (complex 10) increased absorptivity, whereas modifying the imidazole wingtip (complex 11) decreased absorptivity. Modifying the picolinate ligand with methoxy functionality largely had no effect on absorptivity, whereas trifluoromethyl functionalization increased absorptivity and introduced a pronounced band at $460 \mathrm{~nm}$.

The steady-state photoluminescence spectra of complexes 9-14 in $\mathrm{MeCN}$ were measured to understand the changes to the emissive state upon ligand modification. Adding electron density to the cyclometallating ligand led to a slight red shift in the emission spectra $\lambda_{\max }$ value $(577 \mathrm{~nm}$ for $10 \mathrm{vs} 571 \mathrm{~nm}$ for 9), whereas modifying the imidazole wingtip had no effect on $\lambda_{\max }$ (complex 11 vs 9).

Modifying the picolinate ligand was found to have a much more drastic effect, as increasing picolinate-accepting power led to an $83 \mathrm{~nm}$ red shift $(654 \mathrm{~nm}$ for complex $13 \mathrm{vs} 571 \mathrm{~nm}$ for 9). Decreasing accepting power through the addition of methoxy or methyl led to a less-pronounced blue shift (17 $\mathrm{nm}$ ) for both complexes (complexes 12 and 14 vs complex 9). 
From the photoluminescence data, it is clear that picolinate ligand modifications affect emission more than absorption, and that the emission energy can be easily tuned by modifying the picolinate electron donating and accepting strengths. Because of its intrinsic accepting ability, the LUMO likely has high electron density on the picolinate ligand, as was previously described for very similar complexes of (ppy $)_{2} \operatorname{Ir}(\mathrm{pic})$ derivatives. ${ }^{24}$ Photoluminescence data support this hypothesis because emission energy should be lowered by increasing the accepting power of the LUMO-bearing moiety. ${ }^{16}$

Thus, from the electrochemical measurements, it appeared that the molecular HOMO $\left(E_{(S+/ S)}\right)$ was likely localized on the Ir and the cyclometallating moiety of the imidazole ligand (as has been observed in calculations of homoleptic complexes). ${ }^{17}$ The optical measurements indicate that the emissive triplet state $\left(E\left(T_{1}\right)\right)$ is likely composed of a mixed MLCT state, with very little ligand-centered triplet state character in the emissive state, as evidenced by the featureless charge transfer band present for each complex. ${ }^{11}$

The energy levels of complexes 9-14 are compiled in Figure 5 for comparison. From the graph, the ramifications of ligand

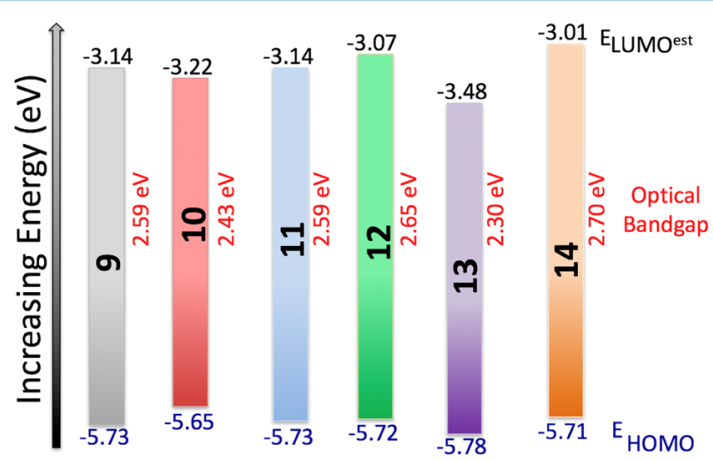

Figure 5. Energy-level diagram for complexes 9-14. The $E_{(\mathrm{S}+/ \mathrm{S})}$ energy level was measured by cyclic voltammetry, and the value was converted to the vacuum scale by the equation $E_{(\text {номо })}(\mathrm{eV})=-4.6-$ $E_{(\mathrm{S}+/ \mathrm{S})}\left(\mathrm{V}\right.$ vs NHE). The $E_{\mathrm{LUMO}}^{\text {est }}$ energy level estimated as the highenergy onset of emission in degassed $\mathrm{MeCN}$. The optical band gap value is the difference between the $E_{\text {HOMO }}$ and $E_{\mathrm{LUMO}}^{\text {est }}$ energy levels.

modification are easier to visualize, especially in the context of band gap energy. For instance, adding electron density to the cyclometallating ligand in complex 10 destabilized the $E_{(\mathrm{S}+/ \mathrm{S})}$ energy level more than $E\left(\mathrm{LUMO}^{\mathrm{est}}\right)$, lowering the band gap energy. Conversely, in complexes 12 and 13, the $E_{\left(S_{+} / S\right)}$ level was slightly destabilized, but $\mathrm{E}\left(\mathrm{LUMO}^{\text {est }}\right)$ was destabilized to a greater degree, leading to overall band gap widening. In complex 13, both $E_{(\mathrm{S}+/ \mathrm{S})}$ and $E\left(\mathrm{LUMO}^{\text {est }}\right)$ were stabilized, with much more stabilization occurring at the $E\left(\mathrm{LUMO}^{\mathrm{est}}\right)$ energy level.

Once we had measured the relevant energy levels for each of the emitters, we then turned to gaining a better understanding of photophysical properties of the complexes in solution and in a variety of matrices. Our first set of measurements involved PLQY $(\Phi)$ data for the complexes (Table 2). While not an IUPAC standard, we chose to reference our PLQY values in solution to a state-of-the-art emitter we had readily available, FIrPic (PLQY $=92 \%$ in dichloroethane, DCE). ${ }^{26,27}$

As has been described for a series of recently published heteroleptic phenylpyridine acetylene-substituted picolinates, the observed PLQY values in solution were much lower than those for FIrPic but similar to those for $\operatorname{Ir}(\text { ppy })_{2}($ pic $)$
Table 2. PLQY Measurements of Complexes 9-14

\begin{tabular}{|c|c|c|c|c|c|c|c|}
\hline complex & 9 & 10 & 11 & 12 & 13 & 14 & Ir816 \\
\hline $\operatorname{PLQY}\left(\Phi_{\text {solution }} \%\right)^{a}$ & 11 & 14 & 9 & 24 & 6 & 10 & $50^{b}$ \\
\hline $\operatorname{PLQY}\left(\Phi_{\text {solid }} \%\right)^{c}$ & & & & 32 & 10 & 34 & \\
\hline $\operatorname{PLQY}\left(\Phi_{\text {solid }} \%\right)^{d}$ & & & & 23 & 7 & 16 & \\
\hline $\operatorname{PLQY}\left(\Phi_{\text {solid }} \%\right)^{e}$ & & & & 28 & 10 & 28 & 59 \\
\hline $\operatorname{PLQY}\left(\Phi_{\text {solid, }} \%\right)^{f}$ & & & & 19 & 3 & 18 & \\
\hline
\end{tabular}

${ }^{a}$ Values taken from measurements made in DCE. Measured relative to FIrPic. ${ }^{26}{ }^{b}$ Literature value. ${ }^{31}{ }^{c}$ Measurement made in the solid state, 26DCZ(ppy) matrix. ${ }^{d}$ Measurement made in the solid state, TcTa + OXD-7 matrix. ${ }^{e}$ Measurement made in the solid state, XTM014 matrix. ${ }^{f}$ Measurement made in the solid state, PMMA matrix.

$(14.7 \%) .^{24}$ In the reported $\operatorname{Ir}(\mathrm{ppy})_{2}$ (pic) complexes, solution excited state lifetime measurements were not indicative of the pure radiative lifetime $\left(\tau_{0}\right)$, and so, we chose to focus on PLQY in solution. Complex 12 exhibited the highest PLQY (24\%), and complex 13 exhibited the lowest (6\%). Complex 10 displayed higher PLQY than complexes 9, 11, and 14 (14\% for 10 compared to $11 \%$ for $9,9 \%$ for 11 , and $10 \%$ for 14 ). Complexes 9-14 also exhibited extremely weak oxygensensitive phosphorescence in $\mathrm{MeCN}$, as has been observed for other complexes. ${ }^{28,29}$ Thus, we concluded that substitution on the wingtip and the cyclometallating ring had little effect on PLQY. Similarly, while methyl substitution on the ancillary ligand greatly enhanced PLQY, more electron-rich methoxy and strongly accepting trifluoromethyl both decreased PLQY in comparison to complex 9.

Because their PLQY values in solution exhibited the most variation, we chose to study the PLQY of emitters 12-14 when dissolved in a variety of host matrices (Table 2 and Supporting Information). The PLQY values for Ir816 were much higher in solution and in XTM014 than for complexes 12-14. Contrary to what was observed in solution, complexes 12 and 14 exhibited similar PLQY values in each of the matrices. Complex 13 was a much less efficient emitter in each trial, perhaps largely because of the energy gap law. PLQY values for each complex in 26DCZ (ppy) were highest overall and lowest in poly(methyl methacrylate-co-butyl methacrylate) (PMMA). These results indicate that the local environment in PMMA favors nonradiative pathways, especially in comparison to $26 \mathrm{DCZ}$ (ppy). ${ }^{30}$ Thus, it was observed that even though PLQY in PMMA (and solution) was low, judicious host selection could boost PLQY values.

Angle-Dependent Photoluminescence. The average orientation of transition dipole moments in thin films of emitters embedded in a host matrix is a useful and interesting aspect to analyze. ${ }^{32}$ In the past years, it became more clear that orienting the transition dipole moments of the emitters horizontally, in plane with the substrate, can improve the light outcoupling efficiency of OLEDs and therefore their EQE. ${ }^{33}$ Several factors can influence the orientation of the emitters, such as the deposition technique, ${ }^{34}$ host material, ${ }^{35}$ particular processing conditions, ${ }^{36}$ and molecular shape of the emitter itself. ${ }^{37} \mathrm{We}$ analyzed the orientation of the average transition dipole moments of compounds 9,10 , and 11 in two different host matrices, poly(9-vinylcarbazole) (PVK) and poly(4-butylphenyl-diphenyl-amine) (poly-TPD). After preparing the solutions (9:1 host/guest ratio), we deposited them on quartz substrates, and we measured the transition dipole moments of the emitters from thin films. The experimental angular dependencies of the p-polarized photoluminescence 
intensities were used as the input for optical simulations using the software OrientExpress. ${ }^{38}$ The angular emission profile of the vertical and horizontal radiating dipoles is simulated based on the thickness and (anisotropic) refractive indices of the layers and the substrate. Hereby, an even distribution of the emitters across the emitting layer is assumed, and the intensities of the contributing dipoles are added accordingly.

The relative weights of the contributions of horizontal and vertical dipoles to the emission profile are then obtained from the measured one by simple linear regression. The comparison of the experimental data with the optical simulations allows one to quantify the degree of the orientation of the transition dipole moments of the emitters in the host. The average orientation of the transition dipole moments can be represented by $\Theta$, the ratio of the horizontal component of the transition dipole moments to the total transition dipole moments. For a fully random distribution of transition dipole moments, $\Theta=0.66$.

As a reference, we use the homoleptic $\operatorname{Ir}(\text { ppy })_{3}$, which is randomly oriented in evaporated layers. ${ }^{39}$ As for 9, 10, and 11, we mix the isotropic emitter in both PVK and poly-TPD (9:1 host/guest ratio) for comparison.

When films have the same thickness and the same host material, PL angle-dependent graphs can be roughly interpreted by comparing the $\mathrm{PL}$ at large $\left(55^{\circ}\right)$ angles with the $\mathrm{PL}$ at small angles $\left(0^{\circ}\right)$.

Horizontal dipoles emit more at small angles (as the dipole oscillating in a plane emits preferentially in directions perpendicular to it), while vertical dipoles emit more at high angles. Therefore, the layers with higher PL at $55^{\circ}$ have average transition dipole moments less horizontally oriented. Figure 6

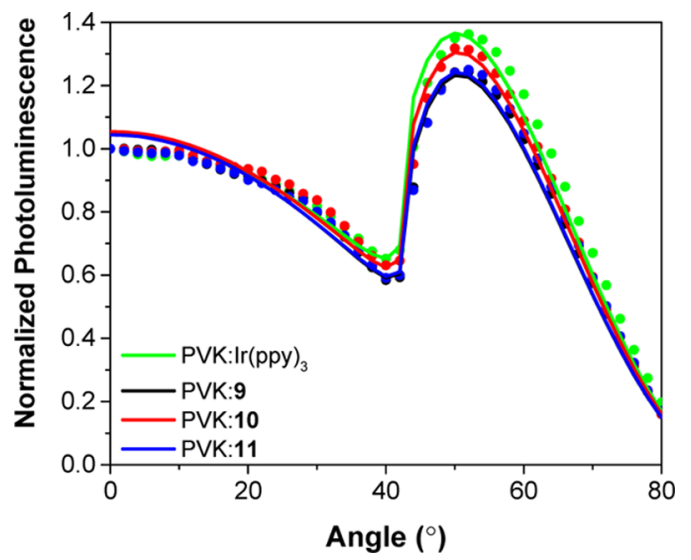

Figure 6. PL angle dependency of $\operatorname{Ir}(\mathrm{ppy})_{3}, \mathbf{9}, \mathbf{1 0}$, and 11 blended in PVK (9:1 host/guest ratio). Experimental data (symbols) and simulated fit (lines).

shows the PL angle dependency of the emitters analyzed in PVK, both experimental measurements and simulated fit (used to quantify the orientation). The transition dipole moments of $\operatorname{Ir}(\text { ppy })_{3}$, the isotropic reference material, are the most vertically oriented, followed by $\mathbf{1 0 . 9}$ and 11 show the same behavior, and their transition dipole moments are the most horizontally oriented. A similar behavior is observed for the emitters in polyTPD, apart from the fact that in poly-TPD, complex $\mathbf{1 0}$ has transition dipole moments slightly more vertically oriented than $\operatorname{Ir}(\mathrm{ppy})_{3}$. Table 3 shows the orientation parameters quantified by combining the experimental data with optical simulation. Here, we can see that all the emitters perform better in polyTPD rather than in PVK (they have higher $\Theta$ ), and that 9 and
Table 3. Orientation of Transition Dipole Moments of $\operatorname{Ir}(\text { ppy })_{3}, 9,10$, and 11, Blended in a Host Matrix of PVK or Poly-TPD

\begin{tabular}{lcc} 
& PVK $(\Theta)$ & PolyTPD $(\Theta)$ \\
$\operatorname{Ir}(\text { ppy })_{3}$ & 0.55 & 0.6 \\
$\mathbf{9}$ & 0.59 & 0.62 \\
$\mathbf{1 0}$ & 0.57 & 0.59 \\
$\mathbf{1 1}$ & 0.59 & 0.63 \\
\hline
\end{tabular}

11 are more favorably oriented compared to the reference isotropic emitter and to $\mathbf{1 0}$. However, all the values for $\Theta$ are lower than 0.66 , which indicates a vertical orientation of the average transition dipole moment.

The apparent preferential vertical orientation of transition dipole moments of $\operatorname{Ir}(\text { ppy })_{3}$ in the polymer hosts is surprising: for this homoleptic complex, one would expect fully random orientation because of its almost isotropic shape. The preferential vertical orientation of $\operatorname{Ir}(\mathrm{ppy})_{3}$ has also been reported for another unoriented, solution-deposited host material. ${ }^{34}$ We note that the preference for the vertical orientation is the largest when using the PVK host material. Below, we briefly discuss a possible contribution to the apparent vertical orientation of the iridium compounds stemming purely from the optical anisotropy of the PVK host.

Solution-deposited layers of PVK have an unusual, positive uniaxial anisotropy $\left(n_{\mathrm{e}}>n_{\mathrm{o}}\right)^{40}$ that may be rationalized in terms of a preferential horizontal orientation of the polymer backbone $^{41}$ with the highly polarizable carbazole side groups orienting such that the long axis of the carbazole moiety is perpendicular to the main chain. Taking into account all possible orientations of the main chain and the carbazole side groups, one then expects the film to be most polarizable in the direction perpendicular to the plane of the film, explaining why $n_{\mathrm{e}}>n_{\mathrm{o}}$. For molecules in a dielectric medium, it is well-known that the polarizability of the medium can couple with the oscillating transition charge density on a dye molecule to produce an effective transition dipole moment $\mu_{\text {eff }}$ that can be larger than the transition dipole moment $\mu_{\text {bare }}$ of the bare molecule. The so-called empty cavity model ${ }^{42}$ predicts:

$$
\mu_{\text {eff }}=\left(\frac{3 n^{2}}{2 n^{2}+1}\right) \mu_{\text {bare }}
$$

The empty cavity model has been found to give an accurate description of the changes in the radiative rate constant for small metal organic luminophores ${ }^{33}$ induced by the polarizability of the environment. If we now take into consideration a uniaxial optically anisotropic medium $\left(n_{\mathrm{o}} \neq n_{\mathrm{e}}\right)$, then based on eq 1, one may expect an apparent preferential orientation of the effective transition dipole moment of an isotropically oriented dye in the direction corresponding to the largest value of the refractive index. In a pragmatic approach, one predicts preferential orientations of the effective transition dipole moment that deviate from the isotropic value by about a percent by simply inserting values for $n_{\mathrm{e}}$ and $n_{\mathrm{o}}$ into 1 . Assuming a slightly simpler relation between the effective transition dipole moment and the refractive index ${ }^{43}\left(\mu_{\text {eff }} \infty n\right)$, one predicts slightly larger deviations from the isotropic values for the orientation, but the differences are still smaller than $4 \%$. In summary, it is conceivable that the positive optical anisotropy of the PVK host contributes to the apparent vertical orientation of the $\operatorname{Ir}(\mathrm{ppy})_{3}$ emitter, but on the basis of the bulk 
dielectric constant, we cannot quantitatively account for the observed deviations. This may indicate the importance of specific molecular interactions between the emitter and the host.

Compared to the homoleptic $\operatorname{Ir}(\mathrm{ppy})_{3}$ emitter with its virtually isotropic shape, the heteroleptic emitters 9 and 11 show an inclination toward more horizontal preferential orientation of transition dipole moments in both polymeric hosts investigated (see Table 3 ). Yet, on an absolute scale, the values of $\Theta$ obtained are indicative of a largely random orientation of the transition dipole moment of these luminophores.

\section{CONCLUSIONS}

Finding new, more efficient emitters for OLEDs is an important challenge in chemistry because lighting devices consume a large amount of energy worldwide. Toward this end, emitting molecules must be rationally designed to fit in to highperformance device configurations. Toward the aim of a deeper understanding of the ramifications of emitter functionalization, we synthesized a series of heteroleptic bis(2-arylimidazole) iridum(III) picolinates with different steric and electronic modifications, from simple alkyl substitution on the cyclometallating ring or the imidazole wingtip group to electronic modification of the picolinate ligand. The complexes were characterized by nuclear magnetic resonance (NMR), UVvisible absorption spectroscopy, photoluminescence spectroscopy, and mass spectrometry, and three complexes were characterized by SC-XRD. Three of the complexes were blended in two different host matrices, and the obtained thin films were characterized by photoluminescent angle dependency to measure the orientation of their average transition dipole moment. The other three complexes were used as dopants in host matrices, and the PLQY of these films was measured. It was determined that ligand substitution played a major role in the relative position of molecular energy levels (and thus emission wavelength) and the observed PLQY. Establishing the structure-property relationship in various phosphorescent emitters for OLEDs is important, as better design rules will come from a larger pool of known complexes. Further studies into structure-property relationships in $\operatorname{Ir}(\mathrm{III})$ emitters are currently underway.

\section{EXPERIMENTAL SECTION}

General Information. All commercially obtained reagents were used as received. Unless otherwise noted, all reactions were performed under an $\mathrm{N}_{2}$ atmosphere. Thin-layer chromatography (TLC) was conducted with Sigma T-6145precoated TLC silica gel $60 \mathrm{~F}_{254}$ aluminum sheets and/or visualized with UV and potassium permanganate staining. Flash column chromatography was performed as described by still using Silicycle P60, 40-63 $\mu \mathrm{m}$ (230-400 mesh). ${ }^{44}{ }^{1} \mathrm{H}$ NMR spectra were recorded on Bruker AVIII-HD (400 or $200 \mathrm{MHz}$ ), and they are reported in ppm using solvent as an internal standard $\left(\mathrm{CDCl}_{3}\right.$ at $\left.7.26 \mathrm{ppm}\right)$. Data are reported as follows: $\mathrm{s}$ = singlet, $\mathrm{d}=$ doublet, $\mathrm{t}=$ triplet, $\mathrm{q}=$ quartet, $\mathrm{p}=$ pentet, $\mathrm{m}=$ multiplet, $\mathrm{b}=$ broad, ap = apparent; coupling constant $(\mathrm{s})$ in $\mathrm{Hz}$; integration. UV-vis spectra were measured with an LS-55 spectrometer. Cyclic voltammetry was measured with a BioLogic S-200 potentiostat. Mass spectra were recorded on a Bruker autoflex MALDI-TOF or ESI mass spectrometer. 2,4,6Triisopropylaniline was prepared according to the literature procedure. $^{45}$ SC-XRD measurements were conducted on a Bruker VENTURE SCXRD instrument. CCDC 1583689 (11), 1584183 (12), 1583690 (13) contain the supplementary crystallographic data for this paper. These data can be obtained free of charge from The Cambridge Crystallographic Data Centre. For the analysis of the orientation of transition dipole moments, three of the Ir complexes synthesized were mixed each with two different host materials, PVK and poly(4butylphenyl-diphenyl-amine) (poly-TPD). The host and guest materials were blended in a 9:1 ratio in chlorobenzene $(0.5 \mathrm{wt}$ $\%)$ and deposited on quartz substrates by spin-coating at 600 or $800 \mathrm{rpm}$, forming 18 to $33 \mathrm{~nm}$ thick films. The angledependent emission of the emitters in the host/guest system was measured in thin films by using a setup described previously. ${ }^{38,46}$ Both layer preparation and angle-dependent measurements were performed in an inert $\mathrm{N}_{2}$ atmosphere $\left(\mathrm{H}_{2} \mathrm{O}\right.$ and $\left.\mathrm{O}_{2}<1 \mathrm{ppm}\right)$ to avoid photochemical degradation and photoluminescence quenching induced by combination of oxygen and UV light. To quantify the orientation of transition dipole moments of the emitters, the experimental measurements were combined with optical simulation by using the OrientExpress software, described in detail in the Supporting Information of ref 38. 2,6-Bis(3-(9H-carbazol-9-yl)phenyl)pyridine (26DCzppy), 4, $4^{\prime}, 4^{\prime \prime}$-tris (carbazol-9-yl)triphenylamine, and 1,3-bis[2-(4-tert-butylphenyl)-1,3,4-oxadiazo-5-yl]benzene (OXD-7) were purchased from lumtec. PMMA and chlorobenzene were purchased from SigmaAldrich.

The optical constants (refractive index, $n$, and extinction coefficient, $k$ ) of the pure host materials, PVK and poly-TPD, were determined experimentally by spectroscopic ellipsometry at various angles of incidence and transmission intensity measurements at $0^{\circ}$ (perpendicular incidence). Optical constants for the host material also containing the molecular emitter (10 wt \%) were assumed to be the same as the pure host. Optical constants were determined using WVASE 32 software from Woollam. Uniaxial optical anisotropy was taken into consideration, and ordinary and extraordinary optical constants were extracted from ellipsometry data of the pure host polymers. These data were used as the input for the optical simulations to quantify the orientation of transition dipole moments.

\section{PHOTOLUMINESCENCE CHARACTERIZATION}

Each complex (10 wt \%) was mixed in different host matrixes. The films were deposited from $10 \mathrm{mg} \mathrm{mL}^{-1}$ solution of complexes in chlorobenzene. Prior to deposition, all solutions were filtered with a $0.2 \mu \mathrm{m}$ pore size filter and spin-coated at $1500 \mathrm{rpm}$ for $60 \mathrm{~s}$ in inert atmosphere onto cleaned quartz substrates. The thin-film photoluminescence spectra and quantum yields were measured in air with a Hamamatsu C9920-02 absolute PLQY measurement system.

General Procedure for Imidazole Formation. 1- $\left(2^{\prime}, 6^{\prime}-\right.$ Diisopropylphenyl)imidazole (1). ${ }^{47}$ A 1 L round-bottom flask equipped with a stirbar was charged with $750 \mathrm{~mL} \mathrm{MeOH}$ and sparged vigorously with $\mathrm{N}_{2}$. After $20 \mathrm{~min}$, 2,6-diispropylaniline $(20 \mathrm{~mL}, 18.8 \mathrm{~g}, 106 \mathrm{mmol})$ and glyoxal $(14.4 \mathrm{~mL}, 106 \mathrm{mmol}$, $40 \%$ in $\mathrm{H}_{2} \mathrm{O}$ ) were added and stirred at rt. After $16 \mathrm{~h}$, large yellow crystals were observed. To this suspension, $\mathrm{NH}_{4} \mathrm{Cl}$ (5.79 $\mathrm{g}, 212 \mathrm{mmol}$ ) was added, a reflux condenser was attached, and the solution was warmed to reflux. Once the crystals had dissolved, formaldehyde ( $16 \mathrm{~mL}, 212 \mathrm{mmol}, 37.5 \%$ in $\mathrm{H}_{2} \mathrm{O}$ ) was added, and heating continued. After $1.5 \mathrm{~h}, 85 \% \mathrm{H}_{3} \mathrm{PO}_{4}(25$ 
$\mathrm{mL}$ ) was added, and the reaction was further refluxed and monitored by TLC. After $6 \mathrm{~h}$, the flask was cooled down to rt, and then to $0{ }^{\circ} \mathrm{C}$, and $\mathrm{pH}$ was adjusted to 9 with $15 \% \mathrm{KOH}$. The organic phase was extracted with $\mathrm{Et}_{2} \mathrm{O}(3 \times 250 \mathrm{~mL})$, washed with $\mathrm{H}_{2} \mathrm{O}(3 \times 500 \mathrm{~mL})$, and concentrated on a rotary evaporator after drying with $\mathrm{MgSO}_{4}$. It was submitted to column chromatography using $650 \mathrm{~mL} \mathrm{SiO}_{2}$ and gradient hexanes to $30 \% \mathrm{EtOAc} /$ hexanes. The product spot was concentrated to yield an off-white solid (12.4 g, 51\% yield). Analytical data matched literature values. ${ }^{1} \mathrm{H}$ NMR $(400 \mathrm{MHz}$, $\left.\mathrm{CDCl}_{3}\right): \delta 7.53(\mathrm{~s}, 1 \mathrm{H}), 7.49(\mathrm{~d}, J=8 \mathrm{~Hz}, 1 \mathrm{H}), 7.30(\mathrm{~d}, 7.1 \mathrm{~Hz}$, $3 \mathrm{H}), 6.99(\mathrm{~s}, 1 \mathrm{H}), 2.45(\mathrm{~m}, J=4.8 \mathrm{~Hz}, 2 \mathrm{H}), 1.19(\mathrm{~d}, J=4.8 \mathrm{~Hz}$, $12 \mathrm{H})$.

1-(2', 4',6'-Triisopropylphenyl)imidazole (2). Reaction performed as for compound 1, yield: $5.0 \mathrm{~g}, 52 \% .{ }^{1} \mathrm{H}$ NMR (400 $\left.\mathrm{MHz} \mathrm{CDCl}_{3}\right): \delta 7.52$ (s, 1H), $7.49(\mathrm{~s}, 1 \mathrm{H}), 7.27$ (s, 2H), 6.77 $(\mathrm{s}, 1 \mathrm{H}), 2.85(\mathrm{~m}, J=4.8 \mathrm{~Hz}, 1 \mathrm{H}), 2.55(\mathrm{~m}, J=6.9 \mathrm{~Hz}, 2 \mathrm{H})$, $1.28(\mathrm{~d}, J=6.9 \mathrm{~Hz}, 6 \mathrm{H}), 1.13(\mathrm{~d}, J=7.0 \mathrm{~Hz}, 6 \mathrm{H}), 1.10(\mathrm{~d}, J=$ $4.8 \mathrm{~Hz}, 6 \mathrm{H}) .{ }^{13} \mathrm{C} \mathrm{NMR}\left(100 \mathrm{MHz}, \mathrm{CDCl}_{3}\right): \delta 150.5,146.3$, $138.8,130.8,129.4,121.8,35.5,28.3,24.6,24.5,24.2$.

General Procedure for Negishi Coupling. 1-(2',6'Diisopropylphenyl)-2-phenylimidazole (3). ${ }^{47}$ A flame-dried Schlenk flask equipped with a stirbar was charged with compound 1 (1.0 g, $4.34 \mathrm{mmol})$ and dry THF $(5 \mathrm{~mL})$ and allowed to cool to $0{ }^{\circ} \mathrm{C}$ with stirring. After $15 \mathrm{~min}, n$-BuLi (1.74 $\mathrm{mL}, 2.5 \mathrm{M}$ in hexanes) was added via a syringe and stirred at 0 ${ }^{\circ} \mathrm{C}$. After $30 \mathrm{~min}, \mathrm{ZnCl}_{2}$ (3.2 mL, $1.9 \mathrm{M}$ in $\left.2 \mathrm{Me}-\mathrm{THF}\right)$ was added via a syringe and stirred at $0{ }^{\circ} \mathrm{C}$. After $30 \mathrm{~min}$, solution was allowed to warm to $\mathrm{rt}$, and then, it was warmed to $40{ }^{\circ} \mathrm{C}$. The solution was concentrated to a total volume of $4 \mathrm{~mL}$, and to that were added dry toluene $(4 \mathrm{~mL})$, iodobenzene $(0.84 \mathrm{~g}$, $0.46 \mathrm{~mL}, 4.1 \mathrm{mmol})$, and $\mathrm{Pd}\left(\mathrm{PPh}_{3}\right)_{4}(0.20 \mathrm{~g}, 0.17 \mathrm{mmol}, 4 \%$ catalyst loading). The solution was warmed to $90{ }^{\circ} \mathrm{C}$ with stirring and was monitored by TLC. After $21 \mathrm{~h}$, the reaction was cooled to rt, and $\mathrm{H}_{2} \mathrm{O}(5 \mathrm{~mL})$ was added. It was washed with $10 \% \mathrm{HCl}(25 \mathrm{~mL})$, dried with $\mathrm{MgSO}_{4}$, concentrated on a rotary evaporator, and submitted to column chromatography using $400 \mathrm{~mL} \mathrm{SiO}_{2}$ and gradient hexanes to $20 \% \mathrm{EtOAC} /$ hexanes. Product fractions were concentrated to yield a beige solid $(1.1 \mathrm{~g}, 87 \%)$. Analytical data matched literature values. ${ }^{1} \mathrm{H}$ NMR (400 MHz, $\left.\mathrm{C}_{6} \mathrm{D}_{6}\right): \delta 7.82(\mathrm{~d}, J=7.1 \mathrm{~Hz}, 2 \mathrm{H}), 7.45$ (d, $J$ $=0.9 \mathrm{~Hz}, 1 \mathrm{H}), 7.18(\mathrm{t}, J=7.8 \mathrm{~Hz}, 1 \mathrm{H}), 7.00(\mathrm{~d}, J=7.9 \mathrm{~Hz}$, $2 \mathrm{H}), 6.95$ (at, $J=6.9 \mathrm{~Hz}, 2 \mathrm{H}), 6.91(\mathrm{ad}, J=7.0 \mathrm{~Hz}, 1 \mathrm{H}), 6.67$ $(\mathrm{d}, J=1.1 \mathrm{~Hz}, 1 \mathrm{H}), 2.58(\mathrm{~m}, J=6.9 \mathrm{~Hz}, 2 \mathrm{H}), 1.06(\mathrm{~s}, 9 \mathrm{H}), 0.97$ (d, $J=6.9 \mathrm{~Hz}, 6 \mathrm{H}), 0.83(\mathrm{~d}, J=6.9 \mathrm{~Hz}, 6 \mathrm{H})$.

1-(2', 4', 6'-Triisopropylphenyl)-2-phenylimidazole (4). Reaction performed as for compound 3, yield: $1.3 \mathrm{~g}, 65 \% .{ }^{1} \mathrm{H}$ NMR (400 MHz, $\left.\mathrm{CDCl}_{3}\right): \delta 7.42-7.39(\mathrm{~m}, 2 \mathrm{H}), 7.29(\mathrm{~s}, 1 \mathrm{H})$, $7.18-7.16(\mathrm{~m}, 3 \mathrm{H}), 7.07(\mathrm{~s}, 2 \mathrm{H}), 6.93(\mathrm{~s}, 1 \mathrm{H}), 2.96(\mathrm{~m}, J=6.9$ $\mathrm{Hz}, 1 \mathrm{H}), 2.44(\mathrm{~m}, J=6.9 \mathrm{~Hz}, 2 \mathrm{H}), 1.30(\mathrm{~d}, J=7.0 \mathrm{~Hz}, 6 \mathrm{H})$, $1.10(\mathrm{~d}, J=6 . \mathrm{Hz}, 6 \mathrm{H}), 0.88(\mathrm{~d}, J=7.0 \mathrm{~Hz}, 6 \mathrm{H}) .{ }^{13} \mathrm{C} \mathrm{NMR}$ $\left(100 \mathrm{MHz}, \mathrm{CDCl}_{3}\right): \delta 150.7,147.3,145.7,132.2,130.7,129.0$, $128.4,128.3,127.4,124.0,122.4,34.6,31.9,28.5,25.4,24.3$, 23.1, 22.9 .

1-(2,6-Diisopropylphenyl)-2-(4" -tert-butylphenyl)imidazole (5). Reaction performed as for compound 3, yield: $1.2 \mathrm{~g}, 81 \%$. ${ }^{1} \mathrm{H}$ NMR $\left(400 \mathrm{MHz}, \mathrm{C}_{6} \mathrm{D}_{6}\right): \delta 7.79(\mathrm{~d}, J=7.8 \mathrm{~Hz}$, $2 \mathrm{H}), 7.45(\mathrm{~d}, J=1.1 \mathrm{~Hz}, 1 \mathrm{H}), 7.23(\mathrm{t}, J=7.8 \mathrm{~Hz}, 1 \mathrm{H}), 7.08$ (at, $J=8.7 \mathrm{~Hz}, 4 \mathrm{H}), 6.71(\mathrm{~d}, J=1.1 \mathrm{~Hz}, 1 \mathrm{H}), 2.58(\mathrm{~m}, J=6.8 \mathrm{~Hz}$, $2 \mathrm{H}), 1.06(\mathrm{~s}, 9 \mathrm{H}), 0.97(\mathrm{~d}, J=6.9 \mathrm{~Hz}, 6 \mathrm{H}), 0.83(\mathrm{~d}, J=6.9 \mathrm{~Hz}$, $6 \mathrm{H}) .{ }^{13} \mathrm{C}$ NMR $\left(100 \mathrm{MHz}, \mathrm{C}_{6} \mathrm{D}_{6}\right): \delta 150.6,146.8,146.0,135.1$, $129.6,129.4,128.5,127.8,127.7,127.5,127.4,126.8,124.9$, $124.11,123.0,34.1,30.8,28.1,24.6,22.5$.
General Procedure for Chloro-Bridged Iridium Dimer Formation. Di- $\mu$-chlorobis(1-(2',6'-diisopropylphenyl)-2phen-2"-ylimidazol-3-yl)diiridium (6). A sealable pressure tube equipped with a stirbar was charged with compound 3 $(0.63 \mathrm{~g}, 2.05 \mathrm{mmol})$ and tridecane $(5 \mathrm{~mL})$ and sparged with $\mathrm{N}_{2}$. After $35 \mathrm{~min},[\operatorname{Ir}(\mathrm{COD}) \mathrm{Cl}]_{2}(0.32 \mathrm{~g}, 0.47 \mathrm{mmol})$ was added, and the tube was sealed under $\mathrm{N}_{2}$. The tube was allowed to be warmed to $240{ }^{\circ} \mathrm{C}$ with stirring and was monitored by TLC. After $15 \mathrm{~h}$, yellow ppt was observed. A crude reaction was submitted directly to column chromatography using $350 \mathrm{~mL}$ $\mathrm{SiO}_{2}$ and a gradient of hexanes to $20 \%$ EtOAc/hexanes. The product spot was concentrated to yield a bright yellow solid (0.60 g, 77\%). ${ }^{1} \mathrm{H}$ NMR (400 MHz, $\left.\mathrm{CDCl}_{3}\right): \delta 7.76(\mathrm{~s}, 4 \mathrm{H})$, $7.57(\mathrm{t}, J=7.6 \mathrm{~Hz}, 4 \mathrm{H}), 7.45-7.38(\mathrm{~m}, 8 \mathrm{H}), 6.51-6.32(\mathrm{~m}$, $8 \mathrm{H}), 6.92(\mathrm{~s}, 4 \mathrm{H}), 6.52(\mathrm{t}, J=7.2 \mathrm{~Hz}, 4 \mathrm{H}), 6.34(\mathrm{~m}, 8 \mathrm{H}), 6.06$ $(\mathrm{d}, J=7.5 \mathrm{~Hz}, 4 \mathrm{H}), 3.0-2.83(\mathrm{~m}, 8 \mathrm{H}), 1.37-1.21(\mathrm{~m}, 42 \mathrm{H})$, $0.94(\mathrm{~d}, J=6.8 \mathrm{~Hz}, 16 \mathrm{H}) .{ }^{13} \mathrm{C}$ NMR $\left(100 \mathrm{MHz}, \mathrm{CDCl}_{3}\right): \delta$ $158.9,146.8,146.7,135.0,135.1,133.7,131.9,130.6,127.9$, 124.8, 124.6, 121.7, 120.2, 29.0, 28.7, 25.2, 24.6, 24.0, 23.4.

Di- $\mu$-chlorobis (1-(2',4', 6'-triisopropylphenyl)-2-phen-2" ylimidazol-3-yl)diiridium (7). Reaction was performed as for compound 7, yield: $0.265 \mathrm{~g}$, 52\%. ${ }^{1} \mathrm{H}$ NMR (400 MHz, $\left.\mathrm{C}_{6} \mathrm{D}_{6}\right)$ : $\delta 8.17(\mathrm{~d}, J=1.5 \mathrm{~Hz}, 4 \mathrm{H}), 7.22(\mathrm{t}, J=7.7 \mathrm{~Hz}, 4 \mathrm{H}), 7.13(\mathrm{dd}, J$ $=7.4 \mathrm{~Hz}, 1.5 \mathrm{~Hz}, 4 \mathrm{H}), 7.06(\mathrm{dd}, J=7.7,1.4 \mathrm{~Hz}, 4 \mathrm{H}), 6.89$ (d, $J$ $=1.5 \mathrm{~Hz}, 4 \mathrm{H}), 6.86(\mathrm{dd}, J=7.8,1.1 \mathrm{~Hz}, 4 \mathrm{H}), 6.69(\mathrm{dt}, J=6.6$, $1.5 \mathrm{~Hz}, 4 \mathrm{H}), 6.51(\mathrm{dt}, J=7.3,1.2 \mathrm{~Hz}, 4 \mathrm{H}), 6.42(\mathrm{dd}, J=7.7,1.5$ $\mathrm{Hz}, 4 \mathrm{H}), 3.01(\mathrm{~m}, J=6.9 \mathrm{~Hz}, 8 \mathrm{H}), 1.13($ at, $J=\mathrm{Hz}, 24 \mathrm{H}), 1.02$ $(\mathrm{d}, J=6.9 \mathrm{~Hz}, 12 \mathrm{H}), 0.77(\mathrm{~d}, J=6.9 \mathrm{~Hz}, 12 \mathrm{H}) .{ }^{13} \mathrm{C} \mathrm{NMR}(100$ $\mathrm{MHz}, \mathrm{CDCl}_{3}$ ): $\delta 158.9,151.1,146.7,146.4,146.2,145.1,135.3$, $131.9,131.5,129.0,128.9,127.8,127.7,122.6,122.5,122.4$, $121.7,120.6,120.4,119.7,35.0,34.7,31.9,29.1,28.8,27.2$, 25.6, 25.2, 25.1, 24.7, 24.4, 24.3, 24.1, 23.5, 22.9. HRMS (ESIMS): Theo. for $\mathrm{C}_{96} \mathrm{H}_{117} \mathrm{ClIr}_{2} \mathrm{~N}_{8},[\mathrm{M}-\mathrm{Cl}]^{+}, 1802.8353$; found for $\mathrm{C}_{96} \mathrm{H}_{117} \mathrm{ClIr}_{2} \mathrm{~N}_{8},[\mathrm{M}-\mathrm{Cl}]^{+}, 1802.8354$.

Di- $\mu$-chlorobis(1-(2',6'-diisopropylphenyl)-2-(4"-tertbutylphen-2"-yl)imidazol-3-yl)diiridium (8). Reaction was performed as for compound 7, yield: $0.235 \mathrm{~g}, 80 \% .{ }^{1} \mathrm{H}$ NMR $\left(200 \mathrm{MHz} \mathrm{CDCl}_{3}\right): \delta 7.83(\mathrm{~m}, 2 \mathrm{H}), 7.63-7.26(\mathrm{~m}, 18 \mathrm{H}), 6.89$ (bs, $4 \mathrm{H}), 6.51-6.32(\mathrm{~m}, 8 \mathrm{H}), 5.91$ (bs, $4 \mathrm{H}), 2.85$ (bs, $4 \mathrm{H})$, $1.54(\mathrm{~s}, 24 \mathrm{H}), 1.30(\mathrm{~s}, 24 \mathrm{H}), 1.04(\mathrm{~s}, 45 \mathrm{H}) .{ }^{13} \mathrm{C}$ NMR $(100$ $\left.\mathrm{MHz}, \mathrm{CDCl}_{3}\right): \delta 159.3,150.0,149.9,147.4,147.3,146.9,146.3$, $133.8,131.9,130.5,129.1,128.7,128.4,127.4,124.6,124.6$, $121.1,119.9,117.0,34.5,34.5,31.7,31.6,31.6,28.9,28.8,23.9$, 23.8, 23.8, 25.1.

General Procedure for Heteroleptic Ir(III) Picolinate Synthesis. Bis(1-(2',6'-diisopropylphenyl)-2-phen-2"'-ylimidazol-3-yl)iridium(III) Picolinate (9). A $25 \mathrm{~mL}$ round-bottom flask equipped with a stirbar and a reflux condenser was charged with dichloromethane $(15 \mathrm{~mL})$ and compound 6 (0.25 g, $0.015 \mathrm{mmol}$ ) and sparged with $\mathrm{N}_{2}$. After $10 \mathrm{~min}$, 2-picolinic acid $(0.006 \mathrm{~g}, 0.045 \mathrm{mmol})$ and $\mathrm{NEt}_{3}(0.006 \mathrm{~g}, 0.011 \mathrm{~mL}, 0.075$ $\mathrm{mmol}$ ) were added, and the reaction was warmed to reflux with stirring and monitored by TLC. After $18 \mathrm{~h}$, the yellow solution was concentrated and passed through an $\mathrm{SiO}_{2}$ plug, first using $20 \% \mathrm{EtOAc} /$ hexanes and then using acetone. Product fractions were concentrated to yield a bright yellow solid (0.060 g, 65\%, based on picolinic acid). ${ }^{1} \mathrm{H} \mathrm{NMR}\left(400 \mathrm{MHz}, \mathrm{CDCl}_{3}\right): \delta 8.34$ $(\mathrm{d}, J=7.5 \mathrm{~Hz}, 1 \mathrm{H}), 7.91-7.83(\mathrm{~m}, 2 \mathrm{H}), 7.53(\mathrm{td}, J=2.5 \mathrm{~Hz}$, $7.2 \mathrm{~Hz}, 4 \mathrm{H}), 7.38-7.24(\mathrm{~m}, 8 \mathrm{H}), 6.88(\mathrm{~d}, J=1.6 \mathrm{~Hz}, 1 \mathrm{H}), 6.81$ $(\mathrm{d}, J=1.7 \mathrm{~Hz}, 1 \mathrm{H}), 6.64-6.58(\mathrm{~m}, 5 \mathrm{H}), 6.47-6.38(\mathrm{~m}, 2 \mathrm{H})$, $6.34(\mathrm{~d}, J=1.7 \mathrm{~Hz}, 1 \mathrm{H}), 6.1(\mathrm{~d}, J=7.8 \mathrm{~Hz}, 1 \mathrm{H}), 6.05(\mathrm{~d}, J=7.8$ $\mathrm{Hz}, 1 \mathrm{H}), 2.81-2.56(\mathrm{~m}, 4 \mathrm{H}), 1.35-0.9(\mathrm{~m}, 24 \mathrm{H}) .{ }^{13} \mathrm{C} \mathrm{NMR}$ $\left(100 \mathrm{MHz}, \mathrm{CDCl}_{3}\right): \delta 173.9,159.6,158.2,153.4,149.1,148.1$, 
$147.1,146.6,146.4,146.3,145.3,137.0,135.5,135.4,133.7$, $133.2,133.1,133.0,130.8,130.7,128.3,128.2,127.7,127.1$, $126.0,125.3,124.9,124.8,124.8,124.7,124.6,122.8,122.3$, $121.8,121.6,120.5,120.1,28.8,28.7,28.5,25.2,24.5,24.0$, 23.8, 23.6, 23.5.

Bis(1-(2',6'-triisopropylphenyl)-2-(4" -tert-butylphen-2" -yl)imidazol-3-yl)iridium(III) Picolinate (10). Reaction was performed as for compound 9 with the exception of 2 equiv picolinate and $\mathrm{NEt}_{3}$ used, yield: $0.020 \mathrm{~g}, 15 \% .{ }^{1} \mathrm{H}$ NMR (400 $\left.\mathrm{MHz}_{\mathrm{CDCl}}\right): \delta 8.29(\mathrm{~d}, J=7.9 \mathrm{~Hz}, 1 \mathrm{H}), 7.82(\mathrm{t}, J=7.7 \mathrm{~Hz}$, $1 \mathrm{H}), 7.64(\mathrm{~d}, J=5.2 \mathrm{~Hz}, 1 \mathrm{H}), 7.52(\mathrm{t}, J=7.7 \mathrm{~Hz}, 2 \mathrm{H}), 7.38-$ $7.26(\mathrm{~m}, 6 \mathrm{H}), 7.21(\mathrm{t}, J=6.4 \mathrm{~Hz}, 1 \mathrm{H}), 6.83(\mathrm{~s}, 1 \mathrm{H}), 6.81(\mathrm{~s}$, $1 \mathrm{H}), 6.77(\mathrm{~s}, 1 \mathrm{H}), 6.54(\mathrm{~d}, J=8.2 \mathrm{~Hz}, 1 \mathrm{H}), 6.47(\mathrm{~d}, J=8.2 \mathrm{~Hz}$, $1 \mathrm{H}), 6.39(\mathrm{~s}, 1 \mathrm{H}), 6.03(\mathrm{~d}, J=8.2 \mathrm{~Hz}, 1 \mathrm{H}), 5.99(\mathrm{~d}, J=8.2 \mathrm{~Hz}$, $1 \mathrm{H}), 2.85(\mathrm{~m}, 1 \mathrm{H}), 2.73(\mathrm{~m}, 1 \mathrm{H}), 2.49(\mathrm{~m}, 1 \mathrm{H}), 1.85(\mathrm{~m}, 1 \mathrm{H})$, $2.05(\mathrm{~m}, 4 \mathrm{H}), 1.26-0.8(\mathrm{~m}, 68 \mathrm{H}) .{ }^{13} \mathrm{C}$ NMR (100 MHz, $\left.\mathrm{CDCl}_{3}\right): \delta 173.9,159.8,158.4,153.7,151.1,150.3,148.4,147.6$, $147.5,146.7,146.6,146.5,145.0,136.6,133.1,133.1,132.7$, $132.6,131.0,130.7,127.7,126.8,125.9,125.1,124.9,124.7$, $124.4,122.3,121.8,121.3,121.2,117.9,117.3,34.5,31.7,31.7$, 31.6, 30.0, 28.9, 28.8, 28.6, 28.4, 25.3, 25.2, 25.1, 24.5, 23.8, 23.7, 23.7. HRMS (ESI-MS): Theo. for $\mathrm{C}_{56} \mathrm{H}_{67} \mathrm{IrN}_{5} \mathrm{O}_{2}$, $[\mathrm{M}+$ $\mathrm{H}]^{+}, 1034.4919$; found for $\mathrm{C}_{56} \mathrm{H}_{67} \mathrm{IrN}_{5} \mathrm{O}_{2},[\mathrm{M}+\mathrm{H}]^{+}$, 1034.4930.

Bis(1-(2', 4',6'-triisopropylphenyl)-2-phen-2"-ylimidazol-3yl)iridium(III) Picolinate (11). Reaction was performed as for compound 9 with the exception of 11 equiv picolinate and 17 equiv $\mathrm{Net}_{3}$, yield: $0.050 \mathrm{~g}, 92 \% .{ }^{1} \mathrm{H} \mathrm{NMR}\left(400 \mathrm{MHz}, \mathrm{CDCl}_{3}\right)$ : $\delta 8.26(\mathrm{~d}, J=7.7 \mathrm{~Hz}, 1 \mathrm{H}), 7.83-7.76(\mathrm{~m}, 2 \mathrm{H}), 7.20-7.05(\mathrm{~m}$, $6 \mathrm{H}), 6.79(\mathrm{~s}, 1 \mathrm{H}), 6.72(\mathrm{~s}, 1 \mathrm{H}), 6.81(\mathrm{~d}, J=1.5 \mathrm{~Hz}, 1 \mathrm{H}), 6.54-$ $6.30(\mathrm{~m}, 7 \mathrm{H}), 6.25(\mathrm{~s}, 1 \mathrm{H}), 6.06-5.94(\mathrm{~m}, 2 \mathrm{H}), 2.94(\mathrm{~m}, 3 \mathrm{H})$, $2.05(\mathrm{~m}, 4 \mathrm{H}), 1.25-0.7(\mathrm{~m}, 36 \mathrm{H}) .{ }^{13} \mathrm{C} \mathrm{NMR}(100 \mathrm{MHz}$, $\left.\mathrm{CDCl}_{3}\right): \delta 173.9,159.6,158.3,153.5,151.4,151.2,149.0,148.1$, $146.6,146.1,146.0,145.9,145.4,136.9,135.7,135.5,133.7$, $133.2,130.7,128.1,127.7,127.0,125.8,125.2,122.8,122.7$, $122.6,122.5,122.4,122.3,121.9,121.8,120.4,120.0,34.6,29.9$, 28.8, 28.8, 28.6, 25.2, 24.7, 24.7, 24.5, 24.3, 24.1, 23.9, 23.7, 23.6. HRMS (ESI-MS): Theo. for $\mathrm{C}_{54} \mathrm{H}_{63} \mathrm{IrN}_{5} \mathrm{O}_{2},[\mathrm{M}+\mathrm{H}]^{+}$, 1006.4606; found for $\mathrm{C}_{54} \mathrm{H}_{63} \operatorname{IrN}_{5} \mathrm{O}_{2},[\mathrm{M}+\mathrm{H}]^{+}, 1006.4619$.

Bis(1-(2',6'-triisopropylphenyl)-2-(phen-2"'-yl)imidazol-3yl)iridium(III) 4-Methylpicolinate (12). Reaction was performed as for compound 9 with the exception of 10 equiv picolinate and $\mathrm{NEt}_{3}$ used, yield: $0.048 \mathrm{~g}, 43 \% .{ }^{1} \mathrm{H}$ NMR (400 $\left.\mathrm{MHz} \mathrm{CDCl}_{3}\right): \delta 8.19(\mathrm{~s}, 1 \mathrm{H}), 7.75(\mathrm{~d}, J=5.5 \mathrm{~Hz}, 1 \mathrm{H}), 7.54$ $(\mathrm{m}, 2 \mathrm{H}), 7.36(\mathrm{~m}, 5 \mathrm{H}), 7.08(\mathrm{dd}, J=5.5,2.0 \mathrm{~Hz}, 1 \mathrm{H}), 6.90(\mathrm{~d}$, $J=1.5 \mathrm{~Hz}, 1 \mathrm{H}), 6.82(\mathrm{~d}, J=1.5 \mathrm{~Hz}, 1 \mathrm{H}), 6.58(\mathrm{~m}, 4 \mathrm{H}), 6.47(\mathrm{t}$, $J=6.8 \mathrm{~Hz}, 1 \mathrm{H}), 6.42(\mathrm{~d}, J=6.8 \mathrm{~Hz}, 1 \mathrm{H}), 6.37(\mathrm{~d}, J=1.6 \mathrm{~Hz}$, $1 \mathrm{H}), 6.12(\mathrm{~d}, J=8.2 \mathrm{~Hz}, 1 \mathrm{H}), 6.06(\mathrm{~d}, J=8.2 \mathrm{~Hz}, 1 \mathrm{H}), 2.79$ $(\mathrm{m}, 1 \mathrm{H}), 2.73(\mathrm{~m}, 1 \mathrm{H}), 2.65(\mathrm{~m}, 1 \mathrm{H}), 2.46(\mathrm{~s}, 3 \mathrm{H}), 2.20(\mathrm{~m}$, $1 \mathrm{H}), 1.24(\mathrm{~d}, J=6.9 \mathrm{~Hz}, 3 \mathrm{H}), 1.22(\mathrm{~d}, J=6.9 \mathrm{~Hz}, 3 \mathrm{H}), 1.17(\mathrm{~d}$, $J=7.0 \mathrm{~Hz}, 3 \mathrm{H}), 1.11(\mathrm{~d}, J=6.9 \mathrm{~Hz}, 3 \mathrm{H}), 1.03(\mathrm{~d}, J=7.1 \mathrm{~Hz}$, $3 \mathrm{H}), 0.95(\mathrm{~m}, 9 \mathrm{H}) .{ }^{13} \mathrm{C} \mathrm{NMR}\left(100 \mathrm{MHz}, \mathrm{CDCl}_{3}\right): \delta 174.1$, $159.6,158.3,152.8,148.9,148.6,148.4,147.1,146.6,146.5$, $146.3,145.6,135.5,135.4,133.7,133.2,133.1,133.1,130.8$, $130.7,128.6,128.2,128.1,127.8,126.0,125.3,124.8,124.8$, $124.6,124.5,122.7,122.2,121.6,121.6,121.5,120.3,120.0$, 28.8, 28.8, 28.7, 28.5, 25.2, 24.7, 24.6, 24.5, 24.0, 23.8, 23.6, 21.5. HRMS (ESI-MS): Theo. for $\mathrm{C}_{49} \mathrm{H}_{53} \mathrm{IrN}_{5} \mathrm{O}_{2},[\mathrm{M}+\mathrm{H}]^{+}$, 936.3823; found for $\mathrm{C}_{49} \mathrm{H}_{53} \mathrm{IrN}_{5} \mathrm{O}_{2},[\mathrm{M}+\mathrm{H}]^{+}, 936.3842$.

Bis(1-(2',6'-triisopropylphenyl)-2-(phen-2"-yl)imidazol-3yl)iridium(III) 4-Trifluoromethylpicolinate (13). Reaction was performed as for compound 9 with the exception of 10 equiv picolinate and $\mathrm{NEt}_{3}$ used, yield: $0.047 \mathrm{~g}, 40 \% .{ }^{1} \mathrm{H}$ NMR (400
$\mathrm{MHz}_{\mathrm{CDCl}}$ ): $\delta 8.60(\mathrm{~s}, 1 \mathrm{H}), 8.10(\mathrm{~d}, J=5.5 \mathrm{~Hz}, 1 \mathrm{H}), 7.55$ $(\mathrm{m}, 2 \mathrm{H}), 7.42(\mathrm{dd}, J=5.1,2.1 \mathrm{~Hz}, 1 \mathrm{H}), 7.38-7.30(\mathrm{~m}, 5 \mathrm{H})$, $6.92(\mathrm{~d}, J=1.5 \mathrm{~Hz}, 1 \mathrm{H}), 6.84(\mathrm{~d}, J=1.5 \mathrm{~Hz}, 1 \mathrm{H}), 6.62(\mathrm{~m}$, $2 \mathrm{H}), 6.54-6.41(\mathrm{~m}, 4 \mathrm{H}), 6.32(\mathrm{~d}, J=1.7 \mathrm{~Hz}, 1 \mathrm{H}), 6.11(\mathrm{~d}, J=$ $8.0 \mathrm{~Hz}, 1 \mathrm{H}), 6.07(\mathrm{~d}, J=8.2 \mathrm{~Hz}, 1 \mathrm{H}), 2.79(\mathrm{~m}, 1 \mathrm{H}), 2.80-2.56$ $(\mathrm{m}, 3 \mathrm{H}), 2.15(\mathrm{~m}, 1 \mathrm{H}), 1.21$ (at, $J=6.9 \mathrm{~Hz}, 6 \mathrm{H}), 1.15(\mathrm{~d}, J=$ $6.9 \mathrm{~Hz}, 3 \mathrm{H}), 1.10(\mathrm{~d}, J=7.0 \mathrm{~Hz}, 3 \mathrm{H}), 1.05(\mathrm{~d}, J=6.9 \mathrm{~Hz}, 3 \mathrm{H})$, $1.03(\mathrm{~d}, J=7.1 \mathrm{~Hz}, 3 \mathrm{H}), 0.93(\mathrm{~m}, 9 \mathrm{H}) .{ }^{13} \mathrm{C}$ NMR $(100 \mathrm{MHz}$, $\left.\mathrm{CDCl}_{3}\right): \delta 172.4,159.4,158.2,155.4,150.1,147.1,147.0,146.6$, $146.4,144.0,138.4(q, J=34.9 \mathrm{~Hz}), 135.4,135.2,133.4,133.2$, $133.0,132.9,131.0,130.8,128.5,128.3,125.9,125.2,125.0$, $124.9,124.8,124.6,124.1,122.9,122.4,122.1,121.9,121.3$, $120.9,120.6,28.8,28.8,28.8,28.8,28.6,28.6,25.2,24.7,24.4$, 24.0, 23.8, 23.7, 23.5. HRMS (ESI-MS): Theo. for $\mathrm{C}_{49} \mathrm{H}_{50} \mathrm{IrN}_{5} \mathrm{O}_{2} \mathrm{~F}_{3}, \quad[\mathrm{M}+\mathrm{H}]^{+}, 990.3540$; found for $\mathrm{C}_{49} \mathrm{H}_{50} \mathrm{IrN}_{5} \mathrm{O}_{2} \mathrm{~F}_{3},[\mathrm{M}+\mathrm{H}]^{+}, 990.3562$.

Bis(1-(2',6'-triisopropylphenyl)-2-(phen-2"-yl)imidazol-3yl)iridium(III) 4-Methoxypicolinate (14). Reaction was performed as for compound 9 with the exception of 10 equiv picolinate and $\mathrm{NEt}_{3}$ used, yield: $0.066 \mathrm{~g}, 58 \% .{ }^{1} \mathrm{H}$ NMR (400 $\left.\mathrm{MHz}, \mathrm{CDCl}_{3}\right): \delta 7.91(\mathrm{~d}, J=2.9 \mathrm{~Hz}, 1 \mathrm{H}), 7.64(\mathrm{~d}, J=6.1 \mathrm{~Hz}$, $1 \mathrm{H}), 7.52(\mathrm{~m}, 2 \mathrm{H}), 7.38-7.29(\mathrm{~m}, 5 \mathrm{H}), 6.89(\mathrm{~d}, J=1.6 \mathrm{~Hz}$, $1 \mathrm{H}), 6.81(\mathrm{~d}, J=1.5 \mathrm{~Hz}, 1 \mathrm{H}), 6.76(\mathrm{dd}, J=6.1,1.7 \mathrm{~Hz}, 1 \mathrm{H})$, $6.61-6.51(\mathrm{~m}, 4 \mathrm{H}), 6.46-6.37(\mathrm{~m}, 3 \mathrm{H}), 6.09(\mathrm{~d}, J=8.0 \mathrm{~Hz}$, $1 \mathrm{H}), 6.03(\mathrm{~d}, J=8.2 \mathrm{~Hz}, 1 \mathrm{H}), 3.93,(\mathrm{~s}, 3 \mathrm{H}), 2.75-2.55(\mathrm{~m}$, $3 \mathrm{H}), 2.2(\mathrm{~m}, 1 \mathrm{H}), 1.21(\mathrm{at}, J=6.9 \mathrm{~Hz}, 6 \mathrm{H}), 1.15(\mathrm{~d}, J=6.9 \mathrm{~Hz}$, $3 \mathrm{H}), 1.09$ (d, $J=7.0 \mathrm{~Hz}, 3 \mathrm{H}), 1.03(\mathrm{~d}, J=6.8 \mathrm{~Hz}, 3 \mathrm{H}), 1.03$ (d, $J=7.1 \mathrm{~Hz}, 3 \mathrm{H}), 0.93(\mathrm{~m}, 9 \mathrm{H}) .{ }^{13} \mathrm{C} \mathrm{NMR}\left(100 \mathrm{MHz} \mathrm{CDCl}_{3}\right)$ : $\delta 173.8,166.6,159.7,155.3,149.5,148.3,147.1,146.7,146.5$, $146.4,145.6,135.5,133.7,133.2,133.1,133.2,130.8,130.7$, $128.2,128.1,126.0,125.4,124.9,124.5,122.7,122.3,121.6$, $120.3,119.9,114.7,112.0,56.18,28.8,28.7,28.5,25.2,24.7$, $24.5,24.0,23.9,23.7,23.5$. HRMS (ESI-MS): Theo. for $\mathrm{C}_{49} \mathrm{H}_{53} \mathrm{IrN}_{5} \mathrm{O}_{3},[\mathrm{M}+\mathrm{H}]^{+}, 952.3772$; found for $\mathrm{C}_{49} \mathrm{H}_{53} \mathrm{IrN}_{5} \mathrm{O}_{3}$, $[\mathrm{M}+\mathrm{H}]^{+}, 952.3796$.

\section{ASSOCIATED CONTENT}

\section{Supporting Information}

The Supporting Information is available free of charge on the ACS Publications website at DOI: 10.1021/acsomega.8b00137.

Selected spectra and crystallographic information (PDF) Crystallographic data for complex 11 (CIF) Crystallographic data for complex 12 (CIF) Crystallographic data for complex 14 (CIF)

\section{AUTHOR INFORMATION}

\section{Corresponding Author}

*E-mail: mdkhaja.nazeeruddin@epfl.ch (M.K.N.).

\section{ORCID}

Sadig Aghazada: 0000-0002-7568-4481

Stefan C. J. Meskers: 0000-0001-9236-591X

René A. J. Janssen: 0000-0002-1920-5124

Henk J. Bolink: 0000-0001-9784-6253

Mohammad Khaja Nazeeruddin: 0000-0001-5955-4786

\section{Author Contributions}

All authors have given approval to the final version of the manuscript.

\section{Notes}

The authors declare no competing financial interest. 


\section{ACKNOWLEDGMENTS}

The authors acknowledge SNSF NRP 70 project; number: 407040 154056, European Commission H2020-ICT-2014-1, SOLEDLIGHT project, grant agreement no.: 643791 and the Swiss State Secretariat for Education, Research and Innovation (SERI), and CTI 15864.2 PFNM-NM, the HZB-HU Graduate School "hybrid4energy," and Solaronix, Aubonne, Switzerland. A.H. acknowledges support from special funding for energy research, managed by Prof. Andreas ZÜTTEL, Funds no. 563074. Part of work was performed in the framework of the TripleSolar (ERC Adv grant no. 339031) project, and received funding from the Ministry of Education, Culture and Science (Gravity program 024.001.035).

\section{REFERENCES}

(1) Baldo, M. A.; Lamansky, S.; Burrows, P. E.; Thompson, M. E.; Forrest, S. R. Very High-Efficiency Green Organic Light-Emitting Devices Based on Electrophosphorescence. Appl. Phys. Lett. 1999, 75, 4.

(2) Adachi, C.; Baldo, M. A.; Thompson, M. E.; Forrest, S. R. Nearly $100 \%$ Internal Phosphorescence Efficiency in an Organic LightEmitting Device. J. Appl. Phys. 2001, 90, 5048.

(3) Yersin, H.; Rausch, A. F.; Czerwieniec, R.; Hofbeck, T.; Fischer, T. The Triplet State of Organo-Transition Metal Compounds. Triplet Harvesting and Singlet Harvesting for Efficient OLEDs. Coord. Chem. Rev. 2011, 255, 2622-2652.

(4) Baldo, M. A.; O’Brien, D. F.; Thompson, M. E.; Forrest, S. R. Excitonic Singlet-Triplet Ratio in a Semiconducting Organic Thin Film. Phys. Rev. B: Condens. Matter Mater. Phys. 1999, 60, 1442214428.

(5) Papi, K.; Zanoni, S.; Coppo, R. L.; Amaral, R. C. Ir(III) complexes designed for light-emitting Devices: Beyond the Luminescence Color Array. Dalton Trans. 2015, 44, 14559-14573.

(6) Thompson, M. The Evolution of Organometallic Complexes in Organic Light- Emitting Devices. MRS Bull. 2007, 32, 694-701.

(7) Helander, M. G.; Wang, Z. B.; Qiu, J.; Greiner, M. T.; Puzzo, D. P.; Liu, Z. W.; Lu, Z. H. Chlorinated Indium Tin Oxide Electrodes with High Work Function for Organic Device Compatibility. Science 2011, 332, 944-947.

(8) Chang, Y.-L.; Wang, Z. B.; Helander, M. G.; Qiu, J.; Puzzo, D. P.; Lu, Z. H. Enhancing the Efficiency of Simplified Red Phosphorescent Organic Light Emitting Diodes by Exciton Harvesting. Org. Electron. 2012, 13, 925-931.

(9) Zhao, Q.; Yu, M.; Shi, L.; Liu, S.; Li, C.; Shi, M.; Zhou, Z.; Huang, C.; Li, F. Cationic iridium(III) Complexes with Tunable Emission Color as Phosphorescent Dyes for Live Cell Imaging. Organometallics 2010, 29, 1085-1091.

(10) Baranoff, E.; Curchod, B. F. E.; Monti, F.; Steimer, F.; Accorsi, G.; Tavernelli, I.; Rothlisberger, U.; Scopelliti, R.; Grätzel, M.; Nazeeruddin, M. K. Influence of Halogen Atoms on a Homologous Series of Bis-Cyclometalated iridium(III) Complexes. Inorg. Chem. 2012, 51, 799-811

(11) Baranoff, E.; Curchod, B. F. E. FIrpic: Archetypal Blue Phosphorescent Emitter for Electroluminescence. Dalton Trans. 2015, 44, 8318-8329.

(12) Lee, J.; Chen, H.-F.; Batagoda, T.; Coburn, C.; Djurovich, P. I.; Thompson, M. E.; Forrest, S. R. Deep Blue Phosphorescent Organic Light-Emitting Diodes with Very High Brightness and Efficiency. Nat. Mater. 2016, 15, 92-98.

(13) Klubek, K. P.; Dong, S.-C.; Liao, L.-S.; Tang, C. W.; Rothberg, L. J. Investigating Blue Phosphorescent Iridium Cyclometalated Dopant with Phenyl-Imidazole Ligands. Org. Electron. 2014, 15, $3127-3136$

(14) Zhuang, J.; Li, W.; Wu, W.; Song, M.; Su, W.; Zhou, M.; Cui, Z. Homoleptic Tris-Cyclometalated Iridium $(<\mathrm{scp}>\mathrm{iii}</ \mathrm{scp}\rangle)$ Complexes with Phenylimidazole Ligands for Highly Efficient Sky-Blue OLEDs. New J. Chem. 2015, 39, 246-253.
(15) Li, J.; Djurovich, P. I.; Alleyne, B. D.; Yousufuddin, M.; Ho, N. N.; Thomas, J. C.; Peters, J. C.; Bau, R.; Thompson, M. E. Synthetic Control of Excited-State Properties in Cyclometalated Ir(III) Complexes Using Ancillary Ligands. Inorg. Chem. 2005, 44, 17131727.

(16) Huckaba, A. J.; Nazeeruddin, M. K. Strategies for Tuning Emission Energy in Phosphorescent Ir(III) Complexes. Comments Inorg. Chem. 2017, 37, 117-145.

(17) Li, J.; Wang, L.; Sun, K.; Zhang, J. Computational Insights into the Photophysical and Electroluminescence Properties of Homoleptic Fac-Ir $\left(\mathrm{C}^{\wedge} \mathrm{N}\right)_{3}$ Complexes Employing Different Phenyl-DerivativeFeaturing Phenylimidazole-Based Ligands for Promising Phosphors in OLEDs. Dalton Trans. 2016, 45, 3034-3047.

(18) Zhuang, J.; Li, W.; Su, W.; Liu, Y.; Shen, Q.; Liao, L.; Zhou, M. Highly Efficient Phosphorescent Organic Light-Emitting Diodes Using a Homoleptic iridium(III) Complex as a Sky-Blue Dopant. Org. Electron. 2013, 14, 2596-2601.

(19) Udagawa, K.; Sasabe, H.; Cai, C.; Kido, J. Low-Driving-Voltage Blue Phosphorescent Organic Light-Emitting Devices with External Quantum Efficiency of 30\%. Adv. Mater. 2014, 26, 5062-5066.

(20) Jayabharathi, J.; Thanikachalam, V.; Saravanan, K.; Perumal, M. V. New Iridium Complexes with Cyclometalated 2-Arylimidazole Ligands as Highly Efficient Saturated Green Emitters. Spectrochim. Acta, Part A 2012, 91, 158-165.

(21) Jayabharathi, J.; Thanikachalam, V.; Srinivasan, N.; Perumal, M. V. Evidence for Strong Mixing Between the LC and MLCT Excited States in Some Heteroleptic Iridium (III) Complexes. J. Fluoresc. 2011, $21,1585-1597$.

(22) Huckaba, A. J.; Aghazada, S.; Zimmermann, I.; Grancini, G.; Schouwink, P.; Nazeeruddin, M. K.. Exploration of Bis ( Arylimidazole ) Iridium Picolinate Complexes. ChemRxiv 2017, DOI: 10.26434/ chemrxiv.5331460.v1.

(23) Frey, J.; Curchod, B. F. E.; Scopelliti, R.; Tavernelli, I.; Rothlisberger, U.; Nazeeruddin, M. K.; Baranoff, E. Structure-Property Relationships Based on Hammett Constants in Cyclometalated Iridium(iii) Complexes: Their Application to the Design of a Fluorine-Free FIrPic-like Emitter. Dalton Trans. 2014, 43, 5667-5679.

(24) Davidson, R.; Hsu, Y.-T.; Bhagani, C.; Yufit, D.; Beeby, A. Exploring the Chemistry and Photophysics of Substituted Picolinates Positional Isomers in Iridium(III) Bisphenylpyridine Complexes. Dalton Trans. 2017, 36, 2727.

(25) Connelly, N. G.; Geiger, W. E. Chemical Redox Agents for Organometallic Chemistry. Chem. Rev. 1996, 96, 877-910.

(26) Endo, A.; Suzuki, K.; Yoshihara, T.; Tobita, S.; Yahiro, M.; Adachi, C. Measurement of Photoluminescence Efficiency of $\operatorname{Ir}(\mathrm{III})$ Phenylpyridine Derivatives in Solution and Solid-State Films. Chem. Phys. Lett. 2008, 460, 155-157.

(27) Aghazada, S.; Huckaba, A. J.; Pertegas, A.; Babaei, A.; Grancini, G.; Zimmermann, I.; Bolink, H.; Nazeeruddin, M. K. Molecular Engineering of Iridium Blue Emitters Using Aryl N- Heterocyclic Carbene Ligands. Eur. J. Inorg. Chem. 2016, 2016, 5089-5097.

(28) Takizawa, S.-Y.; Ikuta, N.; Zeng, F.; Komaru, S.; Sebata, S.; Murata, S. Impact of Substituents on Excited-State and Photosensitizing Properties in Cationic Iridium(III) Complexes with Ligands of Coumarin 6. Inorg. Chem. 2016, 55, 8723-8735.

(29) Ma, L.; Guo, H.; Li, Q.; Guo, S.; Zhao, J. Visible LightHarvesting Cyclometalated $\operatorname{Ir}($ iii) Complexes as Triplet Photosensitizers for Triplet-Triplet Annihilation Based Upconversion. Dalton Trans. 2012, 41, 10680-10689.

(30) Rausch, A. F.; Thompson, M. E.; Yersin, H. Matrix Effects on the Triplet State of the OLED Emitter Ir(4,6-dFppy)2(pic) (FIrpic): Investigations by High-Resolution Optical Spectroscopy. Inorg. Chem. 2009, 48, 1928-1937.

(31) Zhuang, J.; Li, W.; Wu, W.; Song, M.; Su, W.; Zhou, M.; Cui, Z. Homoleptic Tris-Cyclometalated Iridium(iii) Complexes with Phenylimidazole Ligands for Highly Efficient Sky-Blue OLEDs. New J. Chem. 2015, 39, 246-253.

(32) Schmidt, T. D.; Lampe, T.; Sylvinson M. R., D.; Djurovich, P. I.; Thompson, M. E.; Brütting, W. Emitter Orientation as a Key 
Parameter in Organic Light-Emitting Diodes. Phys. Rev. Appl. 2017, 8, 37001 .

(33) Kim, S.-Y.; Jeong, W.-I.; Mayr, C.; Park, Y.-S.; Kim, K.-H.; Lee, J.-H.; Moon, C.-K.; Brütting, W.; Kim, J.-J. Organic Light-Emitting Diodes with $30 \%$ External Quantum Efficiency Based on a Horizontally Oriented Emitter. Adv. Funct. Mater. 2013, 23, 38963900.

(34) Jurow, M. J.; Mayr, C.; Schmidt, T. D.; Lampe, T.; Djurovich, P. I.; Brütting, W.; Thompson, M. E. Understanding and Predicting the Orientation of Heteroleptic Phosphors in Organic Light-Emitting Materials. Nat. Mater. 2016, 15, 85-91.

(35) Moon, C.-K.; Kim, K.-H.; Lee, J. W.; Kim, J.-J. Influence of Host Molecules on Emitting Dipole Orientation of Phosphorescent Iridium Complexes. Chem. Mater. 2015, 27, 2767-2769.

(36) Komino, T.; Tanaka, H.; Adachi, C. Selectively Controlled Orientational Order in Linear-Shaped Thermally Activated Delayed Fluorescent Dopants. Chem. Mater. 2014, 26, 3665-3671.

(37) Yokoyama, D.; Sakaguchi, A.; Suzuki, M.; Adachi, C. Horizontal Orientation of Linear-Shaped Organic Molecules Having Bulky Substituents in Neat and Doped Vacuum-Deposited Amorphous Films. Org. Electron. 2009, 10, 127-137.

(38) Senes, A.; Meskers, S. C. J.; Greiner, H.; Suzuki, K.; Kaji, H.; Adachi, C.; Wilson, J. S.; Janssen, R. A. J. Increasing the Horizontal Orientation of Transition Dipole Moments in Solution Processed Small Molecular Emitters. J. Mater. Chem. C 2017, 5, 6555-6562.

(39) Liehm, P.; Murawski, C.; Furno, M.; Lüssem, B.; Leo, K.; Gather, M. C. Comparing the Emissive Dipole Orientation of Two Similar Phosphorescent Green Emitter Molecules in Highly Efficient Organic Light-Emitting Diodes. Appl. Phys. Lett. 2012, 101, 253304.

(40) Campoy-Quiles, M.; Nelson, J.; Etchegoin, P. G.; Bradley, D. D. C.; Zhokhavets, V.; Gobsch, G.; Vaughan, H.; Monkman, A.; Ingänas, O.; Persson, N. K.; et al. On the Determination of Anisotropy in Polymer Thin Films: A Comparative Study of Optical Techniques. Phys. Status Solidi C 2008, 5, 1270-1273.

(41) Prest, W. M.; Luca, D. J. The Alignment of Polymers during the Solvent-coating Process. J. Appl. Phys. 1980, 51, 5170-5174.

(42) Schuurmans, F. J. P.; de Lang, D. T. N.; Wegdam, G. H.; Sprik, R.; Lagendijk, A. Local-Field Effects on Spontaneous Emission in a Dense Supercritical Gas. Phys. Rev. Lett. 1998, 80, 5077-5080.

(43) Mohanty, J.; Nau, W. M. Refractive Index Effects on the Oscillator Strength and Radiative Decay Rate of $2\{\}$,3 diazabicyclo[2.2.2] oct-2-Ene. Photochem. Photobiol. Sci. 2004, 3, $1026-1031$.

(44) Still, W. C.; Kahn, M.; Mitra, A. Rapid Chromatographic Technique for Preparative Separations with Moderate Resolution. J. Org. Chem. 1978, 43, 2923-2925.

(45) Liu, J.-Y.; Zheng, Y.; Li, Y.-G.; Pan, L.; Li, Y.-S.; Hu, N.-H. $\mathrm{Fe}(\mathrm{II})$ and $\mathrm{Co}(\mathrm{II})$ Pyridinebisimine Complexes Bearing Different Substituents on Ortho- and Para-Position of Imines: Synthesis, Characterization and Behavior of Ethylene Polymerization. J. Organomet. Chem. 2005, 690, 1233-1239.

(46) Senes, A.; Meskers, S. C. J.; Dijkstra, W. M.; van Franeker, J. J.; Altazin, S.; Wilson, J. S.; Janssen, R. A. J. Transition Dipole Moment Orientation in Films of Solution Processed Fluorescent Oligomers: Investigating the Influence of Molecular Anisotropy. J. Mater. Chem. C 2016, 4, 6302-6308.

(47) Micksch, M.; Tenne, M.; Strassner, T. Synthesis of 1,2-Diaryland 1-Aryl-2-Alkylimidazoles with Sterically Demanding Substituents. Eur. J. Org. Chem. 2013, 2013, 6137-6145. 